\title{
Desmoplastic Ameloblastoma A Case Report
}

\author{
G. Gandhi, A. Amirthagani \\ Thanjavur Medical College and Hospital, Thanjavur, India \\ Email: jagan.vel@gmail.com
}

How to cite this paper: Gandhi, G. and Amirthagani, A. (2017) Desmoplastic Ameloblastoma-A Case Report. Open Journal of Stomatology, 7, 180-185.

https://doi.org/10.4236/ojst.2017.73013

Received: March 14, 2016

Accepted: March 28, 2017

Published: March 31, 2017

Copyright (C) 2017 by authors and Scientific Research Publishing Inc. This work is licensed under the Creative Commons Attribution International License (CC BY 4.0).

http://creativecommons.org/licenses/by/4.0/

\begin{abstract}
The desmoplastic ameloblastoma (DA) is a rare variant of the conventional ameloblastoma. It accounts for only $4 \%$ to $13 \%$ of all ameloblastomas. Desmoplastic ameloblastoma (DA) was included in the World Health Organization Classification of Head and Neck Tumors (WHO-2005) as a variant of ameloblastoma with specific clinical, imaging and histological features. The desmoplastic variant of ameloblastoma usually appears in the anterior and premolar regions as a mixed radiolucent and radiopaque lesion, sometimes resembling a benign fibro-osseous lesion [1]. Ameloblastoma is a locally aggressive tumor that may cause recurrence and in rare cases, malignant transformation with repeated postsurgical recurrences [2] [3]. In this paper we present a case of a 47-year-old female with swelling in the left upper jaw, bopsy of which turned out to be desmoplastic ameloblastoma.
\end{abstract}

\section{Keywords}

Ameloblastoma, Desmoplastic Ameloblastoma, Benign Fibro-Osseous Lesion, Odontogenic Tumor

\section{Introduction}

Until now, only 162 cases have been reported in literature. The DA was first described by Eversole et al. in 1984 as a new type of ameloblastoma with unique histological pattern characterized by the presence of islands of ameloblastic columnar cells surrounding spindle-shaped stellate reticulum like cells in a stroma with marked desmoplasia. The desmoplastic variant of ameloblastoma usually appears in the anterior and premolar regions as a mixed radiolucent and radiopaque lesion, sometimes resembling a benign fibro-osseous lesion.

The main histological types of ameloblastoma are the follicular and plexiform patterns. The desmoplastic ameloblastoma is one of the other less common his- 
tological variants [4]. The desmoplastic variant of ameloblastoma usually appears in the anterior and premolar regions as a mixed radiolucent and radiopaque lesion, sometimes resembling a benign fibro-osseous lesion. A differential diagnosis between the osteoplastic variant and fibro-osseous lesions such as fibrous dysplasia or ossifying fibroma can be very difficult. Different methods of treatment have been described, but most authors agree that the management of solid ameloblastoma should be radical and primary curative. The conservative therapy, such as enucleation, is associated with high rate of recurrences [5].

\section{Case Report}

A 47-year-old female, with non-contributory cultural, social, and medical histories, presented to the out-patient department of otorhinolaryngology, Government Thanjavur Medical College, Thanjavur, Tamilnadu, India. Patient had a history of swelling in the left upper jaw for more than 7 years; it was slow growing and painless. On clinical examination $5 \times 5 \mathrm{~cm}$ smooth swelling seen on the left premolar area (Figure 1). It was hard in consistency, which was painless and uneventful. Teeth 21, 22, 23, 24 and 25 were immobile; there is no displacement of the roots of teeth observed. Coronal view of CT Para nasal sinus revealed a poorly defined, mixed, radiolucent-radiopaque image, suggesting a benign fibro-osseous lesion (Figure 2). No cervical lymph node was palpable. Patient was subjected to incisional biopsy and it was approached by sublabial incision. Small piece about $1 \mathrm{~cm}$ removed from the swelling by gauge and mallet and sent for histopathological examination and it was reported as desmoplastic ameloblastoma.

It was decided to remove the tumour in total and plan for inferior partial maxillectomy (Figure 3 and Figure 4). The whole mass removed (Figure 5) after obtaining informed and written consent from the patient and sent for histopathological examination (Figure 6 and Figure 7) and the report came as desmoplastic ameloblastoma and the margins were free.

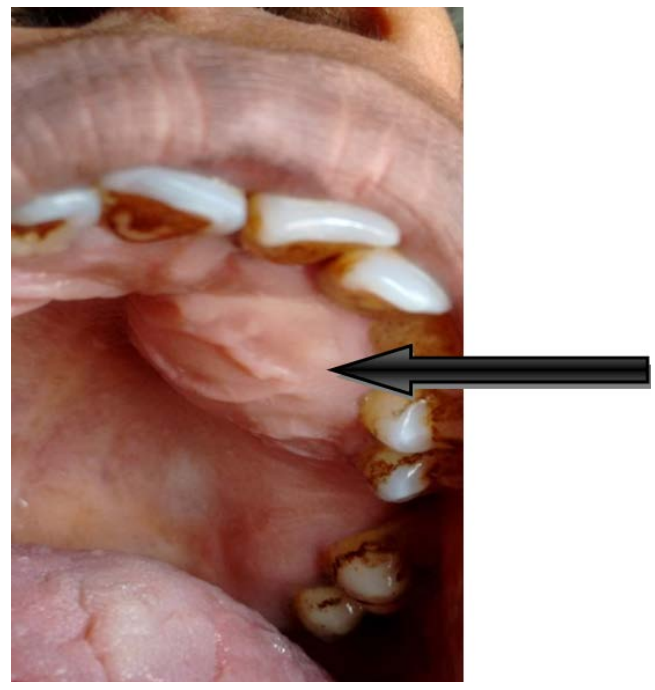

Figure 1. Preoperative picture of the patient showing the mass. 


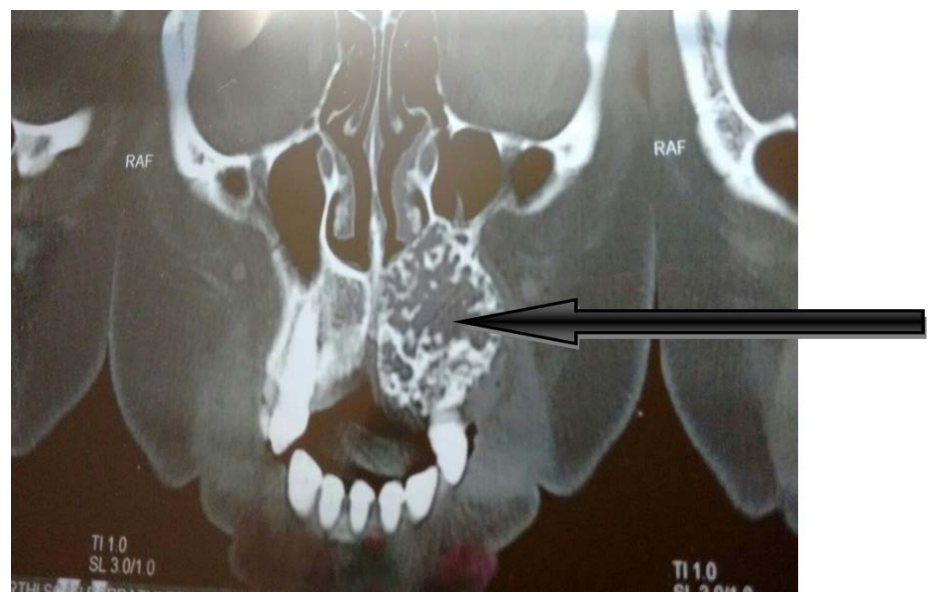

Figure 2. CT PNS.

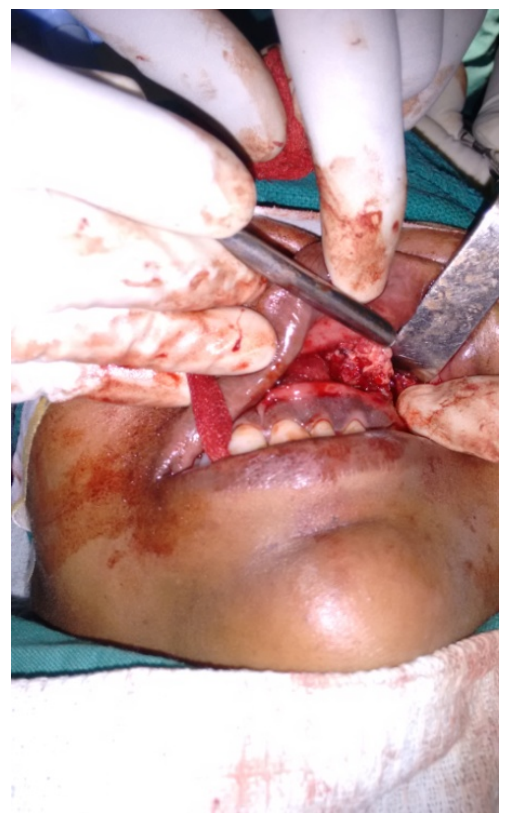

Figure 3. Preoperative picture showing sublabial approach.

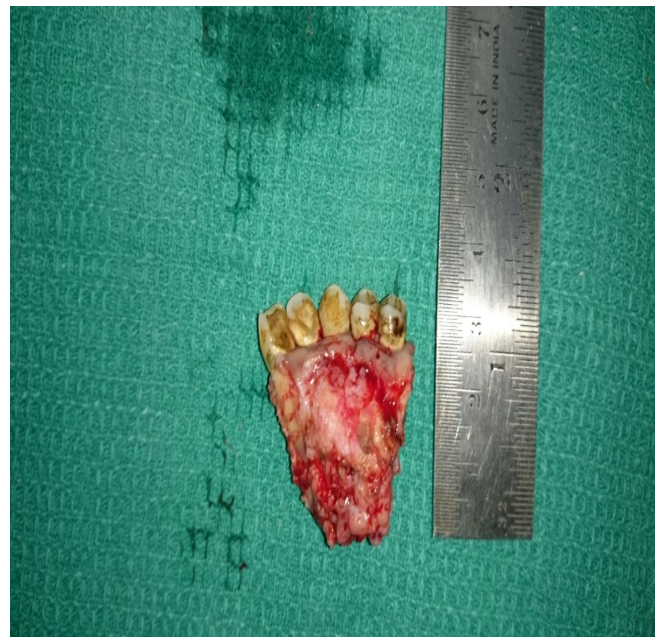

Figure 4. Showing the excised part of mass along with inferior maxilla. 


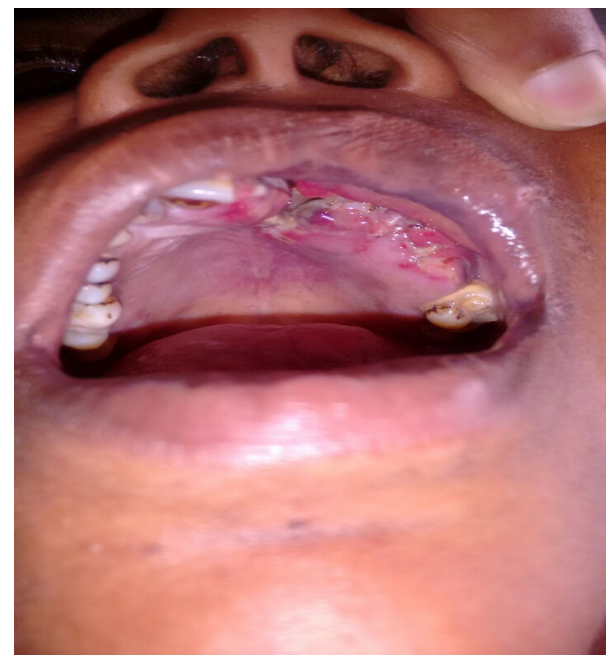

Figure 5. Post operative picture.

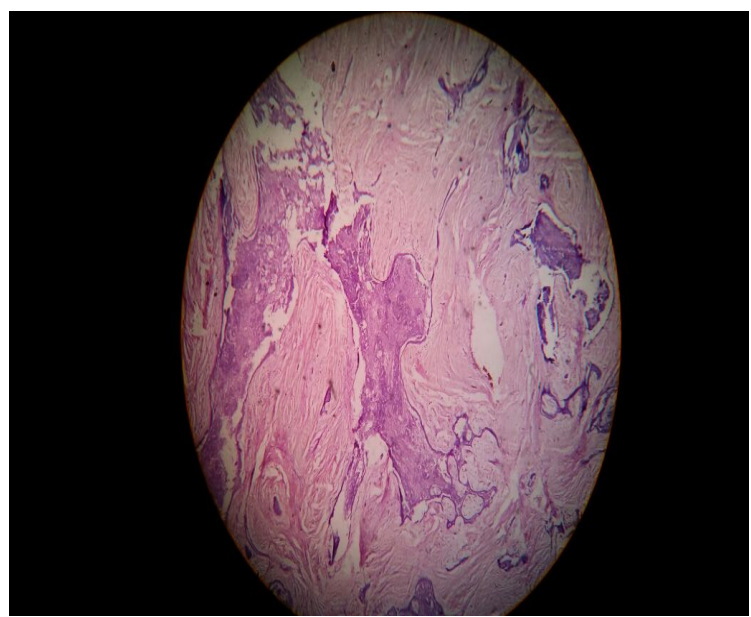

Figure 6. Low power field showing marked stromal desmoplasia characterised by moderately cellular fibrous connective tissue with abundant dense collagen formation and presence of odontogenic columnar epithelium.

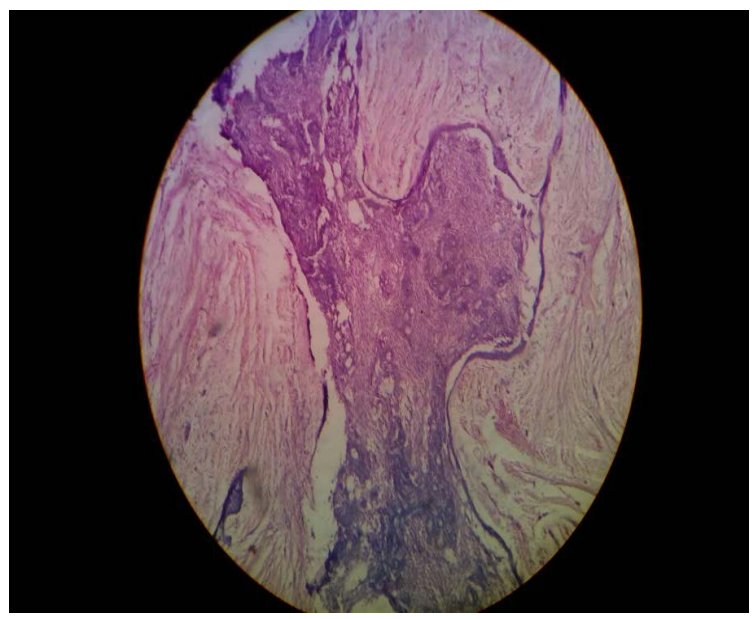

Figure 7. Showing marked stromal desmoplasia characterised by moderately cellular fibrous connective tissue with abundant dense collagen formation and presence of odontogenic columnar epithelium using hemtoxylin and eosin stain. 


\section{Discussion}

The DA is a rare and variant of ameloblastoma, which is characterized by marked stromal desmoplasia. This tumor is most commonly found in the fourth and the fifth decades of life, with no sex predilection [6]. Usually, DA is smaller than other types of ameloblastoma, but if neglected, it can be very extensive and destructive, requiring wide excision. More frequently, it occurs in the anterior part of the jaws, and there is no difference in prevalence between the maxilla and the mandible. The main clinical symptom is a painless swelling with buccal expansion of the mass and teeth displacement [7].

In a recent article, Effiom and Odukoya [8] stated that multilocular radiolucency is the predominant radiographic presentation of the desmoplastic variant of the DA. In contrast, the variant with osteoplasia presented as a mixed radiolucent and radiopaque appearance, thereby mimicking a fibro-osseous lesion.

In 1984, Eversole et al. first described the "desmoplastic ameloblastoma". Histologically, a desmoplastic ameloblastoma consists of an abundant and excessive stromal collagenization or desmoplasia in which irregularly shaped islands of odontogenic epithelium are scattered. Waldron and El-Mofty introduced the term "hybrid lesions" to describe the conditions in which desmoplastic ameloblastoma was located adjacent to follicular or plexiform ameloblastoma. Wakoh et al. [9] presented a case of a patient demonstrating follicular- type ameloblastoma with desmoplasia, in whom radiological findings suggested the coexistence of a fibro-osseous lesion with a solitary cystic lesion and proposed it to be hybrid follicular/desmoplastic ameloblastoma. Desmoplastic ameloblastoma is rare, accounting for approximately $4 \%$ to $13 \%$ of ameloblastomas.

Our case of a 47-year-old female with 7-year history of swelling in the left upper jaw whose biopsy turned out to be desmoplastic ameloblastoma for which the patient was subjected to inferior partial maxillectomy and the margins were confirmed free of the disease.

From this case we learnt that clinicians should suspect about desmoplastic ameloblastoma if a patient attends with complaints of swelling in and around the premolar region.

\section{References}

[1] Waldron, C.A. and El-Mofty, S.K. (1987) A Histopathologic Study of 116 Ameloblastomas with Special Reference to the Desmoplastic Variant. Oral Surgery, Oral Medicine, Oral Pathology, 63, 441-451.

[2] Sun, Z.J., Wu, Y.R., Cheng, N., Zwahlen, R.A. and Zhao, Y.F. (2009) Desmoplastic Ameloblastoma-A Review. Oral Oncology, 45, 752-759. https://doi.org/10.1016/j.oraloncology.2009.01.016

[3] Huang, C.M., Chen, J.Y., Chen, C.H. and Huang, C.J. (2014) Radiotherapy for a Repeatedly Recurrent Ameloblastoma with Malignant Transformation. Head Neck, 36, E1-E3. https://doi.org/10.1002/hed.23257

[4] Eversole, L.R., Leider, A.S. and Strub, D. (1984) Radiographic Characteristics of Cystogenic Ameloblastoma. Oral Surgery, Oral Medicine, and Oral Pathology, 57, 572-577. 
[5] Carlson, E.R. and Marx, R.E. (2006) The Ameloblastoma: Primary Curative Surgical Management. Journal of Oral and Maxillofacial Surgery, 64, 484-494. https://doi.org/10.1016/j.joms.2005.11.032

[6] Beckley, M.L., Farhood, V., Helfend, L.K., et al. (2002) Desmoplastic Ameloblastoma of the Mandible: A Case Report and Review of the Literature. Journal of Oral and Maxillofacial Surgery, 60,194-198. https://doi.org/10.1053/joms.2002.29822

[7] Kaffe, I., Buchner, A. and Taicher, S. (1993) Radiologic Features of Desmoplastic Variant of Ameloblastoma. Oral Surgery, Oral Medicine, Oral Pathology, 76, 525529.

[8] Effiom, O.A. and Odukoya, O. (2011) Desmoplastic Ameloblastoma: Analysis of 17 Nigerian Cases. Oral Surgery, Oral Medicine, Oral Pathology, Oral Radiology, and Endodontology, 111, e27-e31. https://doi.org/10.1016/j.tripleo.2010.06.021

[9] Wakoh, M., Harada, T. and Inoue, T. (2002) Follicular/Desmoplastic Hybrid a Repeatedly Recurrent Desmoplastic Ameloblastoma after Removal and Allobone Graft: Radiographic Features Compared with Histological Changes Ameloblastoma with Radiographic Features of Concomitant Fibro-Osseous and Solitary Cystic Lesions. Oral Surgery, Oral Medicine, Oral Pathology, Oral Radiology, and Endodontology, 94, 774-780. https://doi.org/10.1067/moe.2002.129182

\section{Submit or recommend next manuscript to SCIRP and we will provide best} service for you:

Accepting pre-submission inquiries through Email, Facebook, LinkedIn, Twitter, etc. A wide selection of journals (inclusive of 9 subjects, more than 200 journals)

Providing 24-hour high-quality service

User-friendly online submission system

Fair and swift peer-review system

Efficient typesetting and proofreading procedure

Display of the result of downloads and visits, as well as the number of cited articles

Maximum dissemination of your research work

Submit your manuscript at: http://papersubmission.scirp.org/

Or contact ojst@scirp.org 